\title{
Interpretação de pessoas cegas sobre símbolos 3D em Mapa Tátil de Ambiente Indoor
}

\author{
Niédja Sodré de Araújo* \\ Vivian de Oliveira Fernandes* \\ Mauro José Alixandrini Júnior*
}

Recebido 10 de abril de 2019; aceito 31 de maio de 2019

\begin{abstract}
This paper presents part of the results of a master's research on elaboration of tactile symbols for indoor map made with 3D printer from the rapid prototyping method. The study area confers to the ground floor of the Glauber Rocha Classroom Hall of the Federal University of Bahia located in the city of Salvador-Brazil. From the method "Think Aloud" the tactile map was evaluate with the participation of eight blind people, it was verified that the map was efficient to communicate spatial information of the study area and that the tactile cartography can evaluate in the development of symbols in maps to aid in indoor mobility, that is, in the choice of routes for movement within the buildings.

Key words: visual impairment, tactile map, 3D print, indoor mobility, spatial orientation.
\end{abstract}

\section{Resumo}

Este trabalho apresenta uma pesquisa sobre elaboração de símbolos táteis para mapa indoor fabricado com impressora 3D a partir do método de prototipagem rápida. $\mathrm{A}$ área de estudo confere ao piso térreo do Pavilhão de Aulas Glauber Rocha da Universidade Federal da Bahia localizada na cidade de Salvador-Brasil. A partir do método Think Aloud avaliou-se um mapa tátil com a participação de oito pessoas cegas e verificou-se que o mapa foi útil para comunicar informações espaciais da área de estudo e que a cartografia tátil pode avançar no desenvolvimento de símbolos em

* Escola Politécnica da Universidade Federal da Bahia, Brasil, e-mails: niedja.geo@gmail.com, vivian.fernandes@ufba.br, mauroalixandrini@ufba.br 
mapas para auxiliar na mobilidade indoor, ou seja, na escolha de rotas para deslocamento dentro das edificações.

Palavras-chave: deficiência visual, mapa tátil, impressão 3D, mobilidade interior, orientação espacial.

\section{Resumen}

Este artículo presenta una investigación sobre la elaboración de símbolos táctiles para mapas indoor fabricados con una impresora 3D utilizando el método de creación rápida de prototipos. El área de estudio es la planta baja del Pabellón de Aulas Glauber Rocha de la Universidad Federal de Bahía, ubicada en la ciudad de Salvador-Brasil. A partir del método Think Aloud, se evaluó un mapa táctil con la participación de ocho personas ciegas y se verificó que el mapa era útil para comunicar información espacial del área de estudio y que la cartografía táctil puede avanzar en el desarrollo de símbolos en mapas para ayudar en la movilidad interior, es decir, la elección de rutas para moverse dentro de los edificios.

Palabras claves: discapacidad visual, mapa táctil, impresión 3D, movilidad interior, orientación espacial.

\section{Introdução}

Conforme Sluter (2008) os mapas desempenham a função de atender a necessidade do usuário em realizar análises espaciais para cumprir determinada tarefa ou atividade. Para esta autora, a relação entre o projeto cartográfico e a comunicação cartográfica ocorre por meio da linguagem cartográfica e do uso dos mapas, considerandose a eficiência das análises espaciais como um indicador de sucesso dessa comunicação.

Conforme Almeida (2011), a semiologia gráfica utilizada em mapas, proposta por Jacques Bertin, entre 1967 e 1977, contendo os signos gráficos associados aos conceitos e as imagens associadas aos seus significantes, corresponde ao conjunto das variáveis gráficas visuais (tamanho, valor, textura, cor, orientação e forma) que em sua aplicação prática pode ser convertido em linguagem tátil, com exceção da cor.

Neste contexto, Nogueira [Loch] (2008) corroborando com Almeida (2011), propôs as variáveis gráficas aplicáveis em mapas táteis (Figura 1), com base em Bertin, indicando parâmetros dimensionais mínimos e máximos para que as primitivas gráficas ponto e linha não sejam confundidas entre si ou ponto com área.

A variável volume refere-se à variação de elevação do símbolo em relevo e compõe o conjunto de variáveis gráficas táteis. Assim, a cartografia tátil corresponde a um ramo da cartografia que se ocupa da elaboração de mapas para pessoas cegas ou com baixa visão (Nogueira [Loch], 2008). 

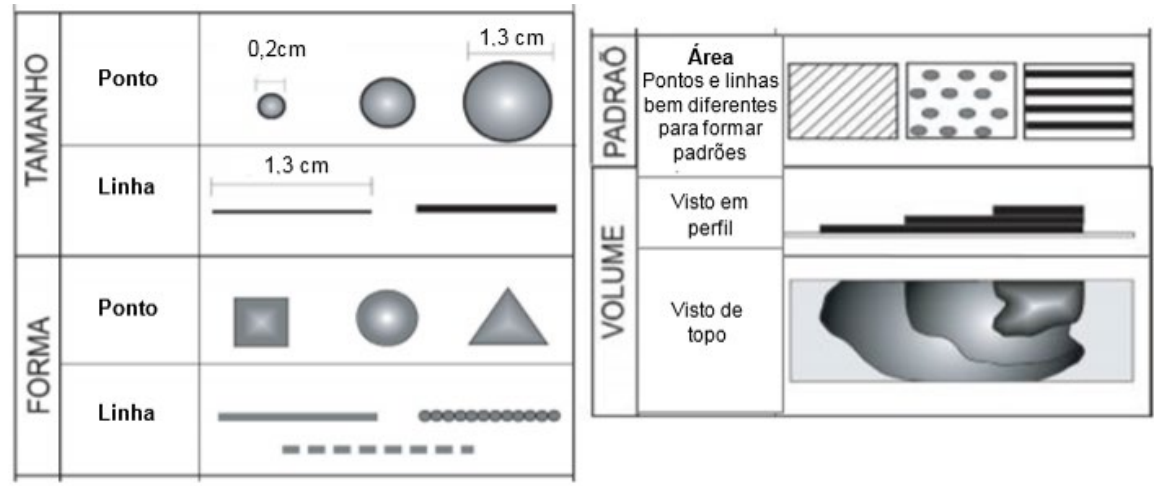

Figura 1. Variáveis gráficas táteis.

Fonte: Nogueira [Loch] (2008).

De acordo com Tatham (citado em Freitas e Ventorini, 2011), os primeiros mapas e diagramas produzidos em relevo, foram propostos pela Escola de Weissenburg em Baviera na Alemanha, em meados do século XIX. Em seguida, as pesquisas sobre procedimentos metodológicos para a confecção de mapas táteis começaram a ser desenvolvidas em outros países da Europa e dos Estados Unido, conforme. No Brasil, a primeira pesquisa de doutorado na área de cartografia tátil foi concluída por Regina Araújo de Almeida [Vasconcellos], em 1993, na Universidade de São Paulo (USP), contribuindo para a divulgação do tema nos ambientes acadêmicos.

$\mathrm{Na}$ América Latina, destacam-se na área da cartografia tátil os projetos realizados pela Universidade Tecnológica Metropolitana (UTEM), no Chile, desde 1987, com trabalhos realizados por pesquisadores do Departamento de Cartografia. Neste contexto, naquele país foi criado o Centro de Cartografia Tátil em 2003 com a finalidade de estudar procedimentos metodológicos para desenvolvimento de uma linguagem gráfica tátil, contando com a colaboração de pesquisadores da USP e da Universidade Estadual Paulista Júlio de Mesquita Filho (UNESP) que compartilham experiências teóricas e práticas sobre produção e avaliação de mapas para pessoas com deficiência visual (Freitas e Ventorini, 2011).

De acordo com Classificação Estatística Internacional de Doenças e Problemas Relacionados à Saúde, a deficiência visual é considerada cegueira quando a visão, ou acuidade visual corrigida é pior que 20/400 e considera-se baixa visão ou visão subnormal, quando o valor da acuidade visual corrigida no melhor olho é menor do que 0,3 e maior ou igual a 0,05 ou seu campo visual é menor do que $20^{\circ}$ no melhor olho com a melhor correção óptica (CBO, 2015).

Conforme Nunes e Lomonaco (2008) as pessoas que perderam a visão antes dos cinco anos de idade são caracterizadas como cegas congênitas e as que perderam a visão após esta idade são cegas adventícias (adquiridas). Deste modo, trabalhar com 
representações gráficas em mapas para o usuário com deficiência visual, significa romper barreiras e enfrentar desafios, principalmente, para a inclusão destas pessoas no contexto escolar (Almeida, 2011).

De acordo com Almeida (2011), os mapas táteis para orientação e mobilidade são elaborados para apoiar as pessoas com deficiência visual a se locomoverem no espaço, sendo o primeiro tipo usado para fornecer informações gerais de uma área e o segundo para detalhar as informações contidas no espaço, visando apoiar a segurança das pessoas cegas ou com baixa visão, durante os seus deslocamentos.

Para MacEachren (1994) os símbolos utilizados em mapas fazem parte da linguagem cartográfica e são usados para localizar os fenômenos espaciais. Deste modo, as relações adequadas entre o nível de medida (ordinal, nominal, intervalar e razão) e as primitivas gráficas (ponto, linha e área) resultam na qualidade da comunicação cartográfica.

Neste contexto, os mapas indoors táteis auxiliam na sinalização para mobilidade das pessoas com deficiência visual em ambientes internos das edificações. A área de estudo desta pesquisa corresponde ao piso térreo do Pavilhão de Aulas Glauber Rocha da Universidade Federal da Bahia (PAF III/UFBA) localizado na cidade de Salvador, Bahia (Brasil) reproduzido em mapa tátil. Diante do exposto, a linguagem cartográfica utilizada neste mapa possibilitou aos usuários cegos escolherem rotas eficientes para prováveis decisões de deslocamento dentro da edificação? Assim, a proposta deste trabalho foi avaliar se a linguagem cartográfica utilizada no mapa tátil indoor 3D do PAF III contribuiu para a escolha de rotas eficientes pelos usuários cegos.

\section{Materiais e Método}

A pessoa com deficiência visual forma os conceitos espaciais, entende as informações geográficas e cria as imagens dos ambientes a partir do sentido tátil, logo, as representações gráficas apreendidas essencialmente pela visão, também podem ser percebidas pelo tato, desde que construídas com esse propósito (Almeida, 2011). Similarmente ao processo da seleção das variáveis visuais em mapas para usuários normovisuais, as associações lógicas também são realizadas na escolha das primitivas gráficas e variáveis táteis, por exemplo, a forma dos símbolos pontuais em mapas 3D. O método consistiu em analisar a planta da área de estudo para generalizar a sua representação, em acordo com as características da impressora 3D e considerando-se os elementos a serem representados, visando compreender a percepção da pessoa cega e atender as suas necessidades como um usuário de mapa indoor. Assim, a planta do pavimento foi ajustada para a manutenção do uso de proporções aproximadas, sequência de sítios, hierarquia de espaços e elementos de circulação vertical do ambiente (rampa, escada, elevador). 
Neste sentido, foram propostos 19 símbolos (Figura 2) com feições linear e pontual, do tipo nominal, variável gráfica forma, com intenção de associá-los ao significado do elemento espacial representado cartograficamente, embasados em modelos artesanais presentes no Catálogo de Símbolos e Materiais de Mapas Táteis para Mobilidade do Laboratório de Cartografia Tátil (labTATE/UFSC), sugestões e adaptações de pesquisas anteriores, outrossim, propostas inéditas.

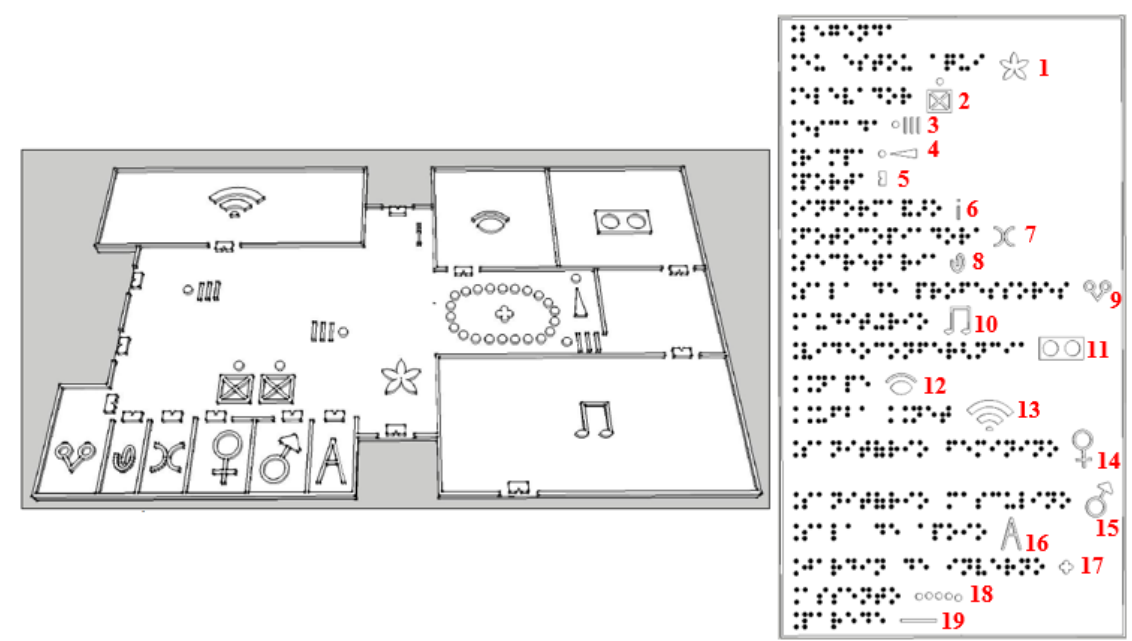

Figura 2. Projeto 3D: piso térreo à esquerda e legenda em Braille. Elaboração: Os autores.

A Figura 2, com símbolos enumerados de 1 a 19 para melhor compreensão do leitor, apresenta o símbolo de assento (18) análogo aos bancos e o de parede (19) ambos com a primitiva gráfica linha e os demais ponto: Eu estou aqui (1); Elevador (2); Escada (3); Rampa (4); Porta (5); Informação (6); Copiadora (7) análogo ao " $x$ " de xerox; Secretaria (8) análogo ao clips; Sala de Professores (9) análogo à coruja, signo de sabedoria; Auditório (10) análogo ao som; Sala de videoconferência (11) análogo à fita cassete; NAPE (12) análogo ao olho, signo de assistir; UFBA /NET (13) análogo ao wi-fi; Sanitário Feminino (14) análogo à vênus, signo feminino; Sanitário Masculino (15) análogo à marte, signo masculino; Sala de Apoio (16); e Jardim de Inverno (17) análogo à flor, todos com $1,5 \mathrm{~mm}$ de elevação, pontos com extensões entre $6 \times 6 \mathrm{~mm}$ e $3 \times 21 \mathrm{~mm}$ e linhas com larguras entre $1 \mathrm{~mm}$ e $3 \mathrm{~mm}$.

A técnica de impressão 3D por prototipagem rápida produz variedades de formas geométricas. Assim, o projeto 3D do mapa foi modelado no software sketchup 8, na escala 1:200 com base em uma planta do piso térreo da área na escala 1:50. Exportou- 
se o projeto para o formato STL compatível com a impressora GTMAX 3D do Espaço Aberto de Criação e Inovação (IHAClab-i) da UFBA.

Através do método de fusão de polímero, imprimiram-se individualmente o piso térreo ( $4 \mathrm{~mm}$ no eixo z, $228 \mathrm{~mm}$ no eixo x e $133 \mathrm{~mm}$ no eixo y) e a legenda ( $4 \mathrm{~mm}$ no eixo z, 278,3 mm no eixo x e 157,6 mm no eixo y). O material utilizado foi a Acrilonitrila Butadieno Estireno (ABS) e os parâmetros de impressão: velocidade máxima igual a $50 \mathrm{~mm} / \mathrm{s}$, velocidade de contorno dos elementos: $20 \mathrm{~mm} / \mathrm{s}$; velocidade do preenchimento sólido dos elementos: $25 \mathrm{~mm} / \mathrm{s}$; velocidade do bico de impressão: 150 $\mathrm{mm} / \mathrm{s}$; diâmetro do bico: 0,4mm; movimento da mesa: $40 \mathrm{~mm} / \mathrm{s}$; temperatura de fusão: $220^{\circ} \mathrm{C}$; e, temperatura da mesa: $110^{\circ} \mathrm{C}$.

\section{Resultados e discussões}

Conforme Peterson (1995) a cognição corresponde ao processo de obtenção de informações por meio de objetos ou ambientes. Assim, os processos cognitivos envolvem: percepção, descoberta, reconhecimento, imaginação, julgamento, memorização, conhecimento e expressão verbal. Neste contexto, a percepção integra reações sensoriais para construir as representações e esquemas do mundo exterior (Golledge, 1999).
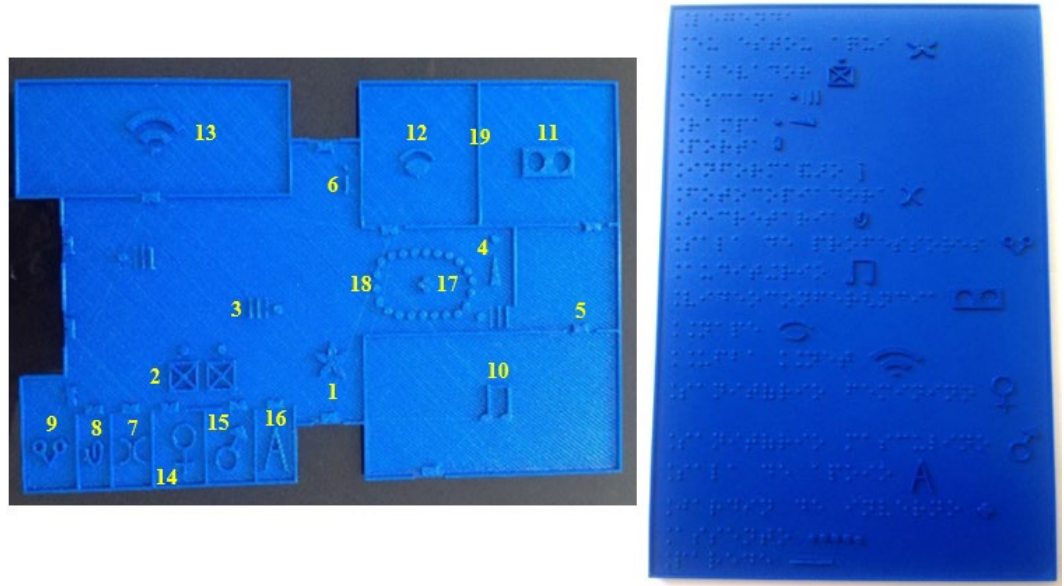

Figura 3. Mapa Tátil 3D: piso térreo à esquerda e legenda à direita.

Elaboração: Os autores.

Para avaliar a linguagem cartográfica do mapa 3D participaram 08 cegos: cinco deles vinculados ao Instituto de Cegos da Bahia (ICB) que não frequentam a área de estudo e três vinculados à UFBA que conhecem a área. No total, três pessoas com 
cegueira congênita e cinco com cegueira adquirida, sendo 03 pessoas do sexo feminino e 05 do sexo masculino com idades entre 30 e 65 anos, 07 deles com nível superior completo e 01 com nível superior incompleto, todos com cegueira total nos dois olhos, 06 deles alfabetizados na escrita latina e Braille e dois alfabetizados apenas na latina.

O teste qualitativo de caráter exploratório foi realizado através do método Think Aloud, utilizado em processos cognitivos durante o uso de um mapa ou imediatamente depois ao uso, quando outras técnicas são bastante limitadas, por exemplo, em pesquisas que exploram a orientação do usuário (Štěrba et al., 2015). Assim, após os usuários cegos interpretarem o mapa tátil indoor (Figura 3), questionou-se individualmente a eles, qual rota faria para sair da posição "Eu estou aqui" (1) e ir para outro local qualquer do piso térreo $(7,8,9,10,11,12,13,14,15,16,18)$.

Notou-se que nesta tarefa, o Núcleo de Apoio à Inclusão do Aluno com Necessidades Educacionais Especiais (NAPE) foi um dos destinos preferenciais dos usuários. As rotas sugeridas foram: i) Destino: auditório (10). Sair do "eu estou aqui (1)", acompanhar a parede (19) da direita, passar ao lado do jardim do inverno (17), passar pela escada (3), seguir para a porta (5) da direita do auditório (10); ii) Destino: NAPE (12). Sair do "eu estou aqui (1)" seguir em frente e na direita para chegar até o NAPE (12); iii) Destino: NAPE (12). Sair do "eu estou aqui", seguir diagonalmente à direita, passar ao lado do jardim de inverno (17), seguir para a porta (5) do NAPE (12); iv) Destino NAPE (12). Sair do "eu estou aqui (1)" seguir em frente, passar pelo jardim de inverno (17) e na direção da direita buscar a porta (5) do NAPE (12); v) Destino: auditório (10). Sair do "eu estou aqui (1)", seguir para a direita, subir a escada (3), seguir a parede (19) até encontrar a porta (5) do auditório (10); vi) Destino: NAPE (12). Sair do "eu estou aqui (1)" e seguir em frente, virar um pouco à direita, buscar a porta (5) do NAPE (12) à diagonal, próximo ao jardim de inverno (17); vii) Destino: UFBA NET (13) Sair do "eu estou aqui (1)", seguir em frente, alcançar a parede (19) e seguir pela esquerda até alcançar a porta (5) da UFBA NET (13); viii) Destino: Sala de Professores (9). Sair do "eu estou aqui (1)" virar à esquerda, passar na frente dos elevadores (2), seguir até encontrar a sala de professores (9) no final deste percurso.

Para avaliar a qualidade dos símbolos, foram utilizadas seis categorias de análise, com base em Jehoel (citado em Araújo, 2018): Sensação ao Toque (textura tátil do símbolo), Detectabilidade (reconhecimento do mesmo símbolo da legenda no mapa), Elevação (relevo ou altura do símbolo “eixo z”), Desenho (singularidade da forma geométrica do símbolo), Dimensões (tamanho das extensões laterais “eixos x, y" do símbolo) e Intuitividade (associação lógica do símbolo com o seu significado). Considerando-se estas categorias, cada símbolo foi avaliado pelo usuário como: péssimo, ruim, regular, bom, excelente. Para a avaliação da cognição do mapa, considerou-se outras duas categorias: layout (percepção geral do mapa) e a legibilidade da legenda em Braille. 
Verificou-se que a singularidade das formas geométricas dos símbolos pode facilitar a interpretação do mapa, por exemplo, o símbolo UFBA NET análogo ao wi-fi, entretanto, elaborar símbolos táteis intuitivos é desafiador, apenas 07 símbolos foram avaliados nesta categoria entre bom e excelente (escada, rampa, parede, assento, sanitário feminino, sanitário masculino e fotocopiadora).

Os símbolos com dimensões maiores, também foram avaliados como os que possuem os melhores desenhos, por exemplo, os símbolos de videoconferência $(20.0 \mathrm{x}$ $10.0 \mathrm{~mm})$, auditório (11.9 x $12 \mathrm{~mm})$, e "eu estou aqui" (12.7 x $12.1 \mathrm{~mm})$. Todavia, os símbolos que tiveram a detectabilidade avaliada entre ruim ou péssima: fotocopiadora (9.1 x $8.9 \mathrm{~mm})$, "eu estou aqui”, informação $(1.0 \times 9.2 \mathrm{~mm})$, rampa $(11.8 \times 4$ $\mathrm{mm})$, secretaria $(6.2 \times 8.6 \mathrm{~mm})$, corresponderam aos menores símbolos, ou então, o seu grau de proximidade com outros símbolos interferiu na individualização/reconhecimento desses. Logo, verificou-se que, o tamanho do símbolo cartográfico para mapas táteis, pode ter dimensão maior do que a área ocupada por uma célula Braille (4.7 x $7.4 \mathrm{~mm}$ ), entretanto, conforme Jehoel (citado em Araújo, 2018), o ideal é que o símbolo não ultrapasse a extensão da ponta do dedo indicador.

Em relação à sensação ao toque e à elevação, todos os símbolos foram avaliados entre bom e excelente, porém, com ressalva para o símbolo de parede (primitiva linha) que poderia ser mais baixo do que os demais, para favorecer a evidência dos símbolos pontuais. Em relação à escrita Braille, todos inferiram que a sensação ao toque não foi satisfatória, devido à aspereza dos pontos, contudo, todos os alfabetizados em Braille (06) leram corretamente a legenda e no caso dos 02 não alfabetizados em Braille, realizou-se a audiodescrição, oralmente, pelos pesquisadores. Quanto ao tempo para reconhecer os 19 símbolos no mapa, os usuários levaram entre 3.6 minutos e 14 minutos, com média de 8 minutos por pessoa.

Os três símbolos identificados mais rapidamente com tempo médio inferior a 7 segundos foram: UFBA NET (13), Sanitário Masculino (15), e videoconferência (11). $\mathrm{E}$ os três símbolos que foram reconhecidos com maior tempo médio foram: rampa (4) com 64 segundos, copiadora (7) com 58 segundos, e, eu estou aqui (1) com 48 segundos.

Sobre o layout do mapa, foram destacadas algumas críticas que dificultaram a percepção dos símbolos e interpretação das informações: proximidade entre alguns símbolos (identificados com espaçamento de apenas $2.3 \mathrm{~mm}$ ); diferentes orientações do mesmo símbolo (rampa) na legenda e no mapa; símbolos com detalhes semelhantes em si: por exemplo, o pingo da letra "i" do símbolo de informação (6) e o ponto que compõe o símbolo de escada (3). Conforme apresenta a Figura 4, esse ponto adicionado junto às representações dos elementos de circulação vertical: escada (3), rampa (4) e elevador (2) teria a função de orientar o usuário frente a este elemento no espaço indoor, contudo, esta analogia informada verbalmente ao usuário, faltou ser 


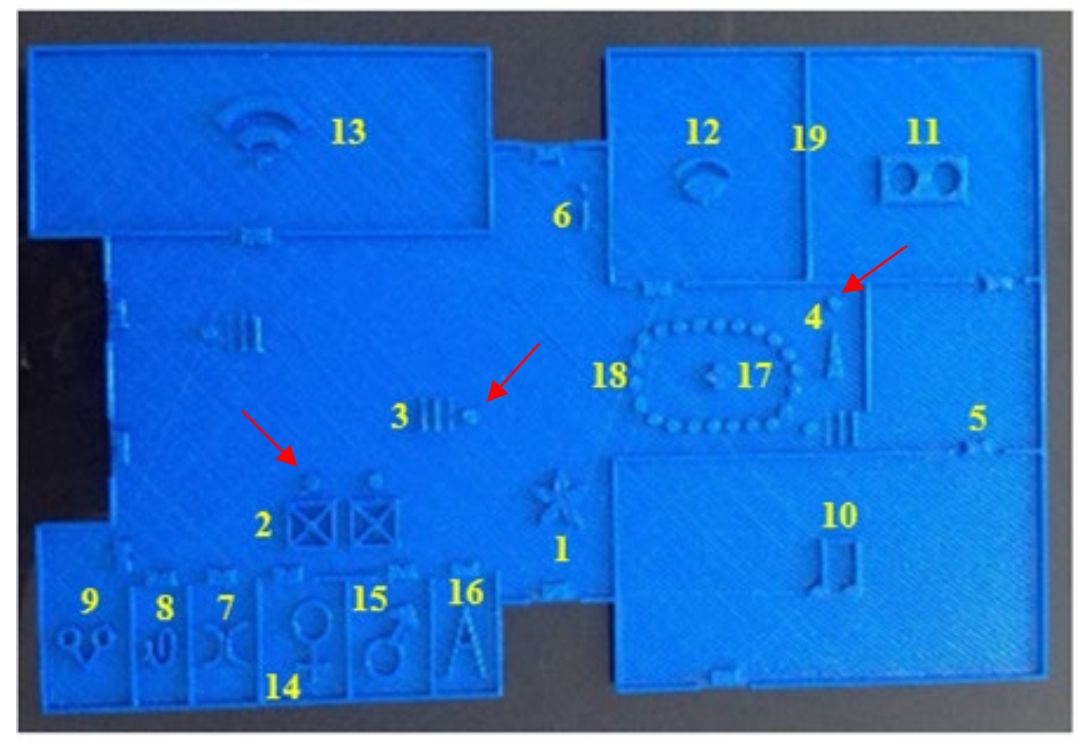

Figura 4. Feições pontuais associadas aos elementos de circulação vertical. Elaboração: Os autores.

explicitada na legenda. Logo, a fim de evitar-se interpretações dúbias ou gerar-se uma linguagem cartográfica tátil complexa, recomenda-se não incluir esse ponto na frente dos elementos de circulação vertical em mapas táteis.

Conforme Almeida (2011), o processo de produção e uso de mapas requer constante revisão, em função das tecnologias disponíveis e das inovações relacionadas aos programas (softwares), equipamentos e recursos multissensoriais disponíveis. Assim, a técnica de impressão 3D tem potencial para apoiar a cartografia tátil na produção de mapas, viabilizando a replicação de modelos de símbolos $3 \mathrm{D}$ em outros mapas, a partir da mesma técnica, entretanto, demanda-se mais estudos para melhorar a qualidade das legendas e dos símbolos construídos com prototipagem rápida.

\section{Conclusões}

Verificou-se que todos os usuários sugeriram rotas eficientes para alcançar os destinos, mencionando os símbolos e os pontos de referência para a sua orientação no espaço indoor, como paredes, portas, escadas, correlacionados às expressões como direita, esquerda, em frente, diagonalmente. Deste modo, a linguagem cartográfica utilizada no mapa possibilitou ao usuário interpretar informações elementares para que se orientasse no deslocamento dentro da edificação. 
A forma geométrica e o conceito dos símbolos precisam ser previamente conhecidos pelo usuário, para estabelecimento de associação lógica entre o desenho do símbolo e o seu significado. Do contrário, a intuitividade provavelmente será indiferente para o usuário. Sobre o posicionamento dos símbolos na legenda, antecedente às suas descrições em Braille, esta pesquisa não obteve críticas a favor ou contra. Para estudos futuros, sugere-se a comparação sobre diferentes formas de apresentação da legenda, para analisar a satisfação e a rapidez do usuário durante a interpretação do mapa.

Recomendam-se, também, investigações sobre as dimensões ideais máximas e mínimas para os símbolos, o espaçamento mínimo entre eles e a avaliação da resistência dos materiais construídos com $\mathrm{ABS}$, ou outros polímeros, para estimar-se a durabilidade dos mapas, bem como, investigação da resistência destes associada às diferentes dimensões dos bicos de impressão, pois, quanto menor o diâmetro, mais complexa e robusta será a estrutura da impressão 3D.

A técnica de prototipagem rápida pode viabilizar a convenção de símbolos táteis, a partir de estudos mais aprofundados sobre semiologia, primitivas gráficas, variáveis gráficas e níveis de medida compatíveis com a cognição tátil, outrossim, materiais e parâmetros de impressão adequados, a citar: velocidades, temperaturas, diâmetro do bico de impressão, dentre outros. Deste modo, estima-se a possibilidade futura de estabelecer-se convenções cartográficas para os projetos de mapas táteis a serem produzidos com impressora 3D, principalmente, os de orientação e mobilidade.

\section{Agradecimentos}

Agradecemos às pessoas cegas participantes, ao NAPE/UFBA, ao ICB, ao IHACLab-i e ao financiamento da bolsa de pesquisa pela Coordenação de Aperfeiçoamento de Pessoal de Nível Superior (CAPES) do Ministério da Educação.

\section{Bibliografia}

Almeida, R.A. (2011). “A cartografia tátil na USP: duas décadas de pesquisa e ensino”, em Freitas, M.I.C. e Ventorini, S.H. (org.), Cartografia tátil: orientação e mobilidade às pessoas com deficiência visual, Jundiaí, Brasil, Paco Editorial, pp. 138-167.

Araújo, N.S. (2018). "Desenvolvimento de símbolos para mapa tátil indoor a partir de impressora 3D", Dissertação de Mestrado, Universidade Federal da Bahia, Salvador, Brasil.

CBO (2015). As condições de Saúde Ocular no Brasil. Recuperado de $<$ http://www.cbo.net.br/novo/publicacoes/Condicoes_saude_ocular_IV.pdf $>$.

Freitas, M.I.C. e Ventorini, S.H. (2011). "Apresentação", em Freitas, M.I.C. e Ventorini, S.H. (org.), Cartografia tátil: orientação e mobilidade às pessoas com deficiência visual, Jundiaí, Brasil, Paco Editorial, pp. 1-28. 
Golledge, R. (1999). "Human Wayfinding and Cognitive Maps", em Golledg E.R. Wayfinding Behavior-Cognitive Mapping and Other Spatial Processes, Baltimore, Estados Unidos, Johns Hopkins.

MacEachren, A.M. (1994). Some Truth with Maps: a primer on Symbolization and dsigner, Estados Unidos, Association of American Geographers.

Nogueira [Loch], R.E. (2008). "Cartografia Tátil: mapas para deficientes visuais", Portal da Cartografia, Londrina, Brasil, vol. 1, no. 1, pp. 35-58.

Nunes, S.S. e Lomonaco, J.F.B. (2008). "Desenvolvimento de conceitos em cegos congênitos: caminhos de aquisição do conhecimento", Psicologia Escolar e Educacional, Brasil, vol. 12, no. 1, pp. 119-138.

Peterson, M.P. (1995). Interactive and animated cartography. University of Michigan, Estados Unidos, Prentice Hall.

Sluter, C.R. (2008). "Uma abordagem sistêmica para o desenvolvimento de projeto cartográfico como parte do processo de comunicação cartográfica", Portal da Cartografia, Londrina, Brasil, vol.1, núm. 1, pp. 1-20.

Štěrba, Z.; Šašinka, Č.; Stachoň, Z.; Štampach., R. e Morong, K. (2015). Selected Issues of Experimental Testing in Cartography. Brno, Masaryk Universit. 